\title{
Antigen-Specific Polyclonal Cytotoxic T Lymphocytes Induced by Fusions of Dendritic Cells and Tumor Cells
}

\author{
Shigeo Koido, ${ }^{1,2}$ Sadamu Homma, ${ }^{2}$ Eiichi Hara, ${ }^{3}$ Yoshihisa Namiki, ${ }^{2}$ Toshifumi Ohkusa, ${ }^{1}$ \\ Jianlin Gong, ${ }^{4}$ and Hisao Tajiri' ${ }^{1}$ \\ ${ }^{1}$ Division of Gastroenterology and Hepatology, Department of Internal Medicine, The Jikei University School of Medicine, \\ Tokyo 105-8461, Japan \\ ${ }^{2}$ Institute of Clinical Medicine and Research, The Jikei University School of Medicine, Tokyo 105-8461, Japan \\ ${ }^{3}$ Saitama Cancer Center Research Institute for Clinical Oncology, 818 Komuro, Ina-machi, Kitaadachi-gun, Saitama 362-0806, Japan \\ ${ }^{4}$ Department of Medicine, Boston University School of Medicine, 650 Albany Street, Room 309, Boston, MA 02118, USA
}

Correspondence should be addressed to Shigeo Koido, shigeo_koido@jikei.ac.jp

Received 29 November 2009; Revised 21 January 2010; Accepted 1 February 2010

Academic Editor: Zhengguo Xiao

Copyright ( 92010 Shigeo Koido et al. This is an open access article distributed under the Creative Commons Attribution License, which permits unrestricted use, distribution, and reproduction in any medium, provided the original work is properly cited.

\begin{abstract}
The aim of cancer vaccines is induction of tumor-specific cytotoxic T lymphocytes (CTLs) that can reduce the tumor mass. Dendritic cells (DCs) are potent antigen-presenting cells and play a central role in the initiation and regulation of primary immune responses. Thus, DCs-based vaccination represents a potentially powerful strategy for induction of antigen-specific CTLs. Fusions of DCs and whole tumor cells represent an alternative approach to deliver, process, and subsequently present a broad spectrum of antigens, including those known and unidentified, in the context of costimulatory molecules. Once DCs/tumor fusions have been infused back into patient, they migrate to secondary lymphoid organs, where the generation of antigen-specific polyclonal CTL responses occurs. We will discuss perspectives for future development of DCs/tumor fusions for CTL induction.
\end{abstract}

\section{Introduction}

A major area of investigation in cancer vaccines involves the design of dendritic cells- (DCs-) based cancer vaccines. DCs can be distinguished from B lymphocytes and macrophages by their abundant expression of costimulatory molecules and efficient ability to prime both CD4+ helper and CD8+ cytotoxic activities [1]. Exogenous antigens from tumor cells can be taken up by DCs and translocated to the cytoplasm, processed, and presented through endogenous pathway. Both immature and mature DCs are capable of processing and presenting MHC-peptide complexes to T cells. Mature DCs are significantly better at CTL induction due to higher expression of MHC and costimulatory molecules, while presentation of antigens by immature DCs, in the absence of proper costimulation, may lead to tolerance induction $[2,3]$. After antigens uptake and inflammatory stimulation, immature DCs in peripheral tissues undergo a maturation process characterized by the upregulation of costimulatory molecules. During this process, mature DCs migrate to the regional lymph nodes, where they present antigens to CD4+ and CD8+ T cells through MHC class I and II pathways [1-3].

Loading MHC class I and II molecules on the cell surface of DCs with peptides derived from defined tumor-associated antigens (TAAs) is the most commonly applicable strategy for DCs-based cancer vaccines. This strategy has some limitations: (1) a limited number of known tumor peptides available in many HLA contexts whose immunogenicity is uncertain and (2) the relatively rapid turnover of exogenous peptide-MHC complexes that results in comparatively low antigen-presentation by DCs. Although DCs pulsed with antigen-specific peptides have been used in clinical trials for cancer patients, clinical responses have been found in a small number of patients $[4,5]$. Another strategies have been developed to load DCs with TAAs, including tumor RNA, tumor lysates, and dying tumor cells to induce antigen-specific CTL responses [6-10]. DCs pulsed with 
apoptotic tumor cell fragments or tumor lysates rely on antigen being cross-presented, all of which are usually not efficient [11]. An alternative strategy for inducing efficient CTL responses is the use of fusion cells generated by fusing DCs and tumor cells by polyethylene glycol (PEG) known as a chemical membrane destabilizing agent [12]. In this approach, multiple TAAs, including both known and unidentified, are delivered to DCs, endogenously processed and presented through MHC class I and II pathways in the context of the potent immune-stimulatory machinery of the DCs [13-15].

\section{DCs/Tumor Fusions Approach}

The chemical agent PEG [12], electroporation [16], and many viruses [17] have been used for the cell fusion strategy. We have used PEG to generate fusions of DCs and tumor cells. In our approach, DCs are usually mixed with tumor cells at a ratio of $10: 1$ in serum-free prewarmed RPMI 1640 medium. After centrifuge, mixed cell pellets are gently resuspended in prewarmed 50\% PEG solution (molecular weight $=1,450) / D M S O$ solution, Sigma-Aldrich, St. Louis, MO; $1 \mathrm{~mL}$ per $5 \times 10^{6}$ cells) for 3 to 5 minutes at room temperature. Subsequently, the PEG solutions are diluted by slow addition and mixed with $1,2,4,8$, and $16 \mathrm{~mL}$ of serum-free prewarmed RPMI medium until $50 \mathrm{~mL}$. The cell pellets are resuspended in prewarmed RPMI 1640 supplemented with $10 \%$ autologous heat-inactivated serum, GM-CSF (1000 units/mL), and IL-4 (500 units/mL) and cultured in a $5 \% \mathrm{CO}_{2}$ atmosphere at $37^{\circ} \mathrm{C}$ for 3 days. The DCs/tumor fusions cannot proliferate but alive until 5 to 7 days after fusion (our unpublished data). Therefore, we have usually cultured fusion cells for 3 days after PEG treatment. After 3 days of culture, DCs/tumor fusion preparations are integrated into a single entity and are loosely adherent to the culture dish. Unfused tumor cells grow firmly attaching to the plates, whereas DCs/tumor fusions are loosely adherent in the culture wells. DCs/tumor fusions can be selected and purified by gentle pipetting, and firmly attached tumor cells are discarded. As this fusion procedure delivers not only the TAAs-epitopes but also the genes encoding the TAAs, DCs/tumors can continue to produce TAAs for several days after fusion [18]. Because fusion efficiency is closely correlated with antitumor immune responses in mice study, DCs/tumor fusions have been harvested on 3 days after fusion process to induce CTL responses in vitro.

There are some methods for enrichment of DCs/tumor fusion cells by FACS cell sorting [19] and the transfection of DCs with Tyr-green fluorescent protein reporter virus [20]. On the other hand, short-term culture of fusion cell preparations can also promote DCs/tumor fusion efficiency and reduce cell aggregates [18]. Therefore, it is not necessary to enrich DCs/tumor fusion cell preparations using special methods. In clinical trials and animal studies, fusion cell preparations, including fused cells, unfused DCs, and unfused tumor cells, have been irradiated before vaccination $[12,18,21,22]$.

\section{Characterization of DCs/Tumor Fusions}

Fusions of DCs and whole tumor cells have the essential elements for processing and presenting TAAs to host immune cells and inducing effective antitumor immune responses (Figure 1). It has been known that there are two different pathways for antigen presentation by DCs. Endogenously synthesized proteins, such as those in viral infections, and certain exogenous antigens are processed and presented through the MHC class I-restricted pathway to CD8+ $\mathrm{T}$ cells [1-3]. In contrast, exogenous antigens are processed through endogenous pathway, a phenomenon called cross-antigen presentation and displayed in association with $\mathrm{MHC}$ class II molecules and recognized by CD4+ T cells [1-3]. Importantly, the fusion process facilitates the introduction of tumor antigen to endogenous antigen processing pathway [23]. It has been reported that DCs/tumor fusions have the ability to process and present intracellular proteins derived from tumor cells [24]. Advantage of DCs/tumor fusions strategy over DCs pulsing with tumor lysates is that endogenously synthesized antigens have better access to MHC class I pathway [25]. Indeed, DCs/tumor fusions vaccine is superior to those involving other methods of DCs loading with antigenic proteins, peptides, tumor cell lysates, or irradiated tumor cells [26].

The membranes of DCs/tumor fusions are integrated into a single cell, whereas the nuclei remain separate in the primary hybrid cells [27]. Therefore, the important advantage in DCs/tumor fusions strategy is that modifications of DCs and tumor cells are independently possible while their characters persist after the fusion. This is an important difference between the DCs/tumor fusions and DCs pulsed with whole tumor cells. The fusions deliver not only the TAAs but also the mRNA encoding the TAAs. It has been reported that there are differences in the translation efficiency of mRNA to protein between immature DCs and mature DCs [15]. Stimulation of DCs by Toll-like receptor (TLR) signaling results in increased expression of peptide/MHC class I and II complexes, costimulatory molecules (CD80 and CD86), and IL-12 [28]. Recent studies have shown that cross-presentation is based on the transfer of proteasome substrates that are transcriptionally upregulated by heat-treatment of tumor cells $[29,30]$. Therefore, we have generated fusions of TLR-stimulated DCs and heat-treated tumor cells to induce efficient CTL induction (Figure 2). This modified DCs/tumor fusions have been more potent than conventional fusions generated with immature DCs and unheated tumor cells, as demonstrated by (1) upregulation of heat-shock proteins (HSPs), MHC class I and II, TAAs, CD80, CD86, CD83, and IL-12; (2) activation of CD4+ and CD8+ T cells able to produce IFN$\gamma$ at higher levels; and (3) potent induction of antigenspecific CTL responses [30]. Synergism between TLRstimulated DCs and heat-treated tumor cells may enhance the immunogenicity of DCs/tumor fusions and may provide promising means of inducing therapeutic CD4+ and CD8+ T cells. 


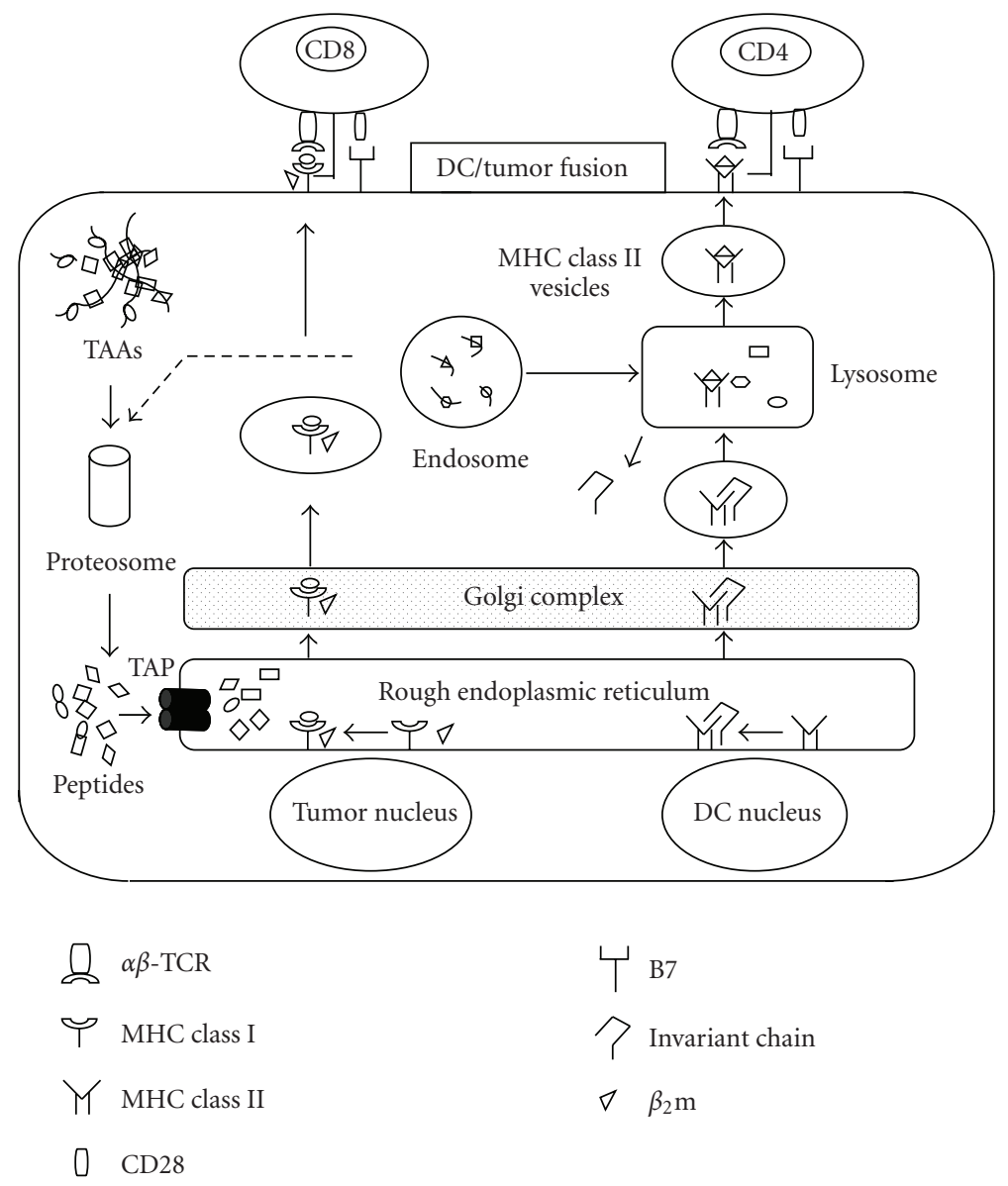

FIGURE 1: Antigen-processing and -presentation by DCs/tumor fusions. DCs/tumor fusions express MHC class I and II, costimulatory molecules (CD80 and CD86), and multiple tumor-associated antigens. The DCs/tumor fusions are able to process multiple tumor-derived peptides and MHC class I peptides derived from tumor and DCs. They form MHC class I-peptide complexes, in the endoplasmic reticulum, which are transported to the cell surface of fusions and presented to CD8+ T cells. The DCs/tumor fusions can also synthesize MHC class II peptides derived from DCs in the endoplasmic reticulum, which are transported to the cytoplasm, where MHC class II-peptide complexes are assembled with multiple tumor-derived peptides. These complexes are presented to CD4+ T cells, which are essential for induction of antigen-specific polyclonal CTLs.

\section{Induction of CTL Responses by DCs/Tumor Fusions in Animal Models}

MUC1, a carcinoma-associated antigen, is a high-molecularweight glycoprotein overexpressed in human breast, pancreatic, colon, and other carcinomas [31, 32]. Therefore, we have used MUC1-transgenic (MUC1.Tg) mice as a preclinical model in initial animal studies. Although the MUC1.Tg mice expressing human MUC1 was unresponsive to MUC1 antigen, MUC1-specific CTL responses could be efficiently generated by fusions of DCs and MUC1-positive carcinoma cells [33]. Moreover, MUC1-specific CTLs rejected the established MUC1-expressing tumor metastases [33-35]. On the other hand, there was little if any anti-MUC1 CTL responses could be induced with DCs transfected with MUC1 RNA in MUC1.Tg mice [10]. Unresponsiveness to the MUC1 antigen could be reversible by vaccination with DCs/tumor fusions expressing MUC1. Therefore, the fusions vaccine may represent an effective strategy for the treatment of human tumors. The DCs/tumor fusions vaccine not only provided protection against challenge with tumor cell, but also regressed the established tumors, including melanoma $[11,19,24,36-40]$, colorectal $[12,20,34,41-48]$, breast [4953], esophageal [54], pancreatic [55], hepatocellular [5660], lung [61,62], laryngeal [63], renal cell carcinoma [64], sarcoma [65-67], myeloma [68-73], mastocytoma [74], and neuroblastoma [75].

The transplantable tumor models have been contributed as the primary screening tools for cancer vaccine development. However, tumor in these models grows very quickly without the multiple stages of cancer development found in human cancers. Mice with spontaneous tumor development provide a powerful tool to study the efficacy of CTL induction, since they mimic tumor development in humans. We have used a transgenic murine model (MMT mice) expressing polyomavirus middle $\mathrm{T}$ oncogene and MUC1 antigen [32, 76]. The MMT mice developed mammary carcinoma between the ages of 65-108 days 


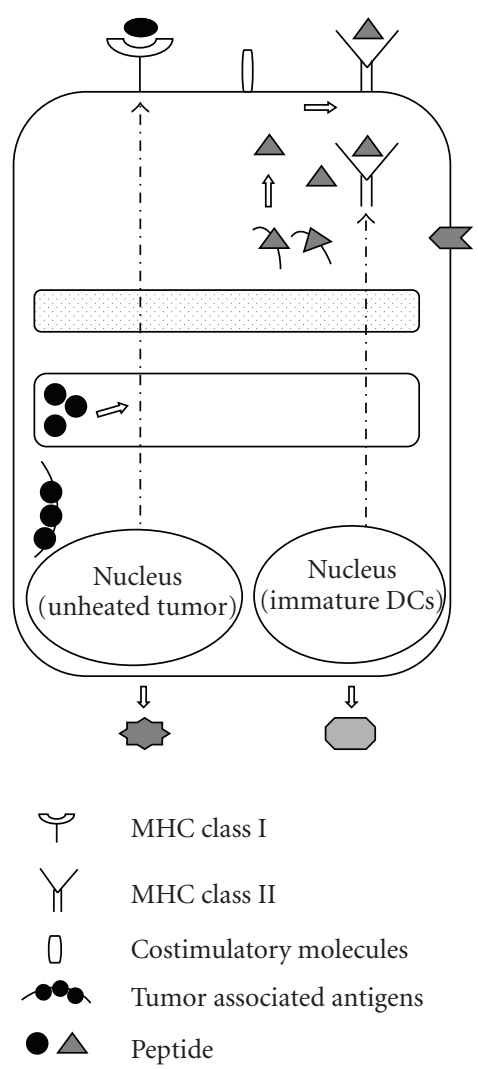

(a)

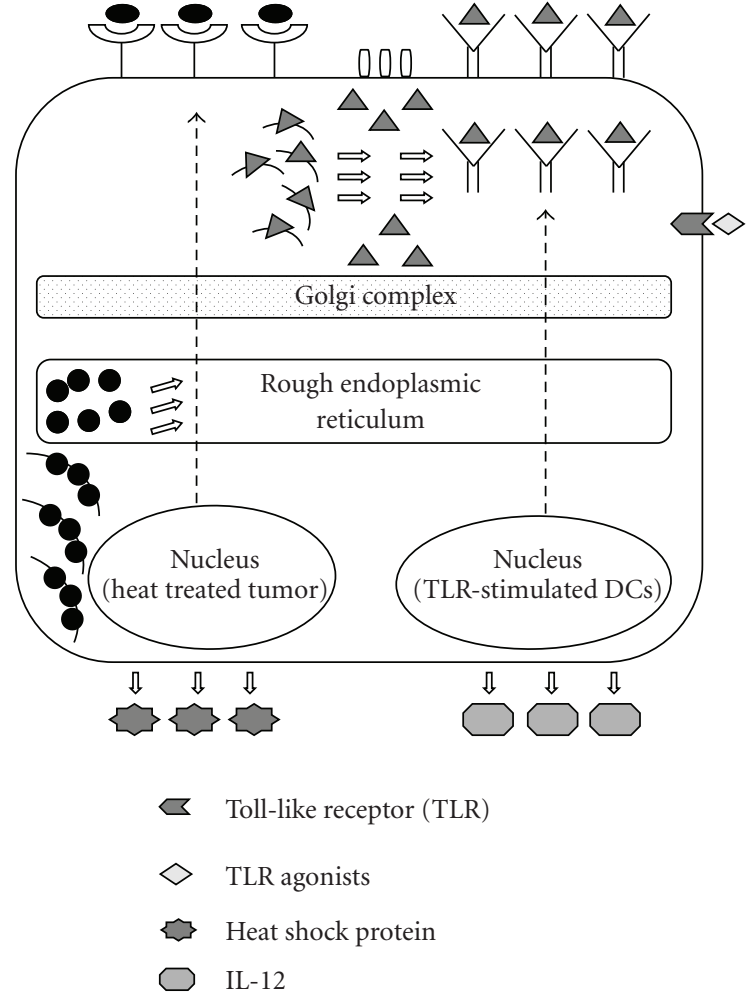

(b)

FIGURE 2: Modified DCs/tumor fusions. (a) Conventional fusions generated with immature DCs and unheated tumor cells express MHC class I and II, costimulatory molecules (CD80 and CD86), Toll-like receptor (TLR), and multiple tumor-associated antigens (TAAs). (b) Fusions generated by fusing TLR-stimulated DCs and heat-stressed tumor cells have characteristic phenotype with upregulation of multiple HSPs, MHC class I and II, costimulatory molecules (CD80 and CD86), maturation marker CD83, multiple TAAs, and IL-12. As compared with conventional fusions (a), synergism between TLR-stimulated DCs and heat-stressed tumor cells enhances the immunogenicity of DCs/tumor fusions.

with $100 \%$ penetrance. Prophylactic vaccination of MMT mice with DCs/tumor fusions induced polyclonal CTLs against spontaneous mammary carcinoma cells and rendered $57 \%-61 \%$ of the mice free of the disease at the end of experiment (180 days) [50, 51]. In other mice models that develop spontaneous hepatocellular carcinoma [58] or gastrointestinal cancer [43], DCs/tumor fusions were also capable of inducing CTL responses.

\section{How to Induce CTL Responses by DCs/Tumor Fusions}

The DCs/tumor fusions possess the properties of both parent cells. Fusions of DCs and tumor cells result in the formation of a heterokaryon that combines DC-derived MHC class I and II, costimulatory molecules, efficient antigen-processing and -presentation machinery, and abundant tumor-derived MHC class I and TAAs (Figure 1) [12]. The DCs/tumor fusions approach facilitates the entry of TAAs that are synthesized de novo in the fusions. As a result, whole TAAs can be processed and presented through both MHC class I and II pathways on the DC compartment in the context of costimulatory molecules [12]. The advantage of DCs/tumor fusions over DCs loading with tumor lysates or peptide is that endogeneously synthesized TAAs have better access to MHC class I and II pathways [25]. Effective TAAs processing and presentation in DCs/tumor fusions are crucial for potent CTL induction.

MHC class I and II molecules are important for antigen processing and presentation and subsequent activation of $\mathrm{CD} 8+$ and CD4+ T cells, respectively. To investigate the role of MHC class I- and II-restricted antigen presentation and the activation of CD4+ and CD8+ T cells by DCs/tumor fusion cells, we have created four types of DCs/tumor fusions with intact or deficient expressions of MHC class I and/or II molecules by using several kinds of DCs from MHC class I and/or II knockout mice and tumors: (1) wild type fusions (WT-FCs), (2) MHC class I knockout fusions (IKOFCs), (3) MHC class II knockout fusions (IIKO-FCs), and (4) MHC class I and II knockout fusions (I/IIKO-FCs) [77]. We observed differential impairment of antitumor immunity induced by fusions generated with DCs from MHC class I and/or II knockout mice. Immunization of 
mice with IKO-FCs resulted in slightly decreased capacity for CTL induction, tumor prevention, and tumor treatment, compared with immunization with WT-FCs. In contrast, immunization with IIKO-FCs abolished IFN- $\gamma$ production of CD4+ and CD8+ T cells and the induction of CTLs and exhibited severely impaired antitumor immunity. Therefore, MHC class II antigen presentation targeting activation of $\mathrm{CD} 4+\mathrm{T}$ cells may be indispensable in antitumor immunity. The presentation of TAAs on MHC class II is essential for the activation of $\mathrm{CD} 4+\mathrm{T}$ cells and the induction of efficient CD8+ CTL responses. It has been demonstrated that predominant effector cells are CD8+ CTLs, as most tumors express only MHC class I molecules. However, there are increasing evidences that $\mathrm{CD} 4+\mathrm{T}$ cells play a more direct role beyond delivery of assistance in the generation of efficient antitumor immunity [78]. Unlike CD8+ T cells, CD4+ T cells may contribute to antitumor immunity through diverse mechanisms. It has been well documented that CD4+ T cells provide help to $\mathrm{CD} 8+\mathrm{T}$ cells by activating APCs through CD40-CD40L interaction [79] and/or IL-2 production [80]. In addition to providing help in the priming phase, $\mathrm{CD} 4+\mathrm{T}$ cells are also essential in the effector phase [81], in which they are required for the maintenance of CD8+ CTLs in vivo and the infiltration of CTLs at the tumor site [82]. Importantly, it has been also reported that adoptive cell transfer of antigenspecific CD4+ T cells can control tumor growth [83].

\section{Stimulation of CD4+ and CD8+ T Cells by DCs/Tumor Fusions}

Efficient CTL induction requires the stimulation of both CD4+ and CD8+ T cells [84]. We have previously reported that DCs/tumor fusions migrated to the regional lymph nodes, where they were closely associated with CD4+ and CD8+ T cells. Moreover, DCs/tumor fusions localized to the $\mathrm{T}$ cell area in the regional lymph nodes and formed clusters with CD4+ and CD8+ T cells [34]. Simultaneous recognition of cognate peptides presented by MHC class I and II molecules on DCs/tumor fusions is essential in the induction of efficient CTLs $[84,85]$. DCs/tumor fusions, unlike DCs, do not have to take up exogenous TAAs. Moreover, DCs or Langerhans cells in the patient body can intake the degraded DCs/tumor fusions that have been vaccinated. Therefore, both direct antigen-presentation by DCs/tumor fusions and cross-presentation by DCs in the patients with cancer can participate in $\mathrm{CD} 4+$ and $\mathrm{CD} 8+$ $\mathrm{T}$ cell-activation $[14,45,84]$. It has been well known that mature DCs are significantly better at CTL induction due to higher expression of MHC and costimulatory molecules, while presentation of TAAs by immature DCs, in the absence of proper costimulation, may lead to tolerance induction [86]. Recent studies indicate that TLRs directly regulate both cancer immunity and tolerance through innate immune responses mediated by regulatory T cells (Tregs), DCs, and other immune cells [87]. Coadministration of TLR ligands with DCs/tumor fusion-based vaccine regulates the function of Tregs and DCs through some mechanisms: (1) stimulation of fusions by TLR signaling results in the increased expres- sion of peptide/MHC class I and II complexes, costimulatory molecules (CD80 and CD86), and cytokines (IL-12) [18], and (2) TLR signaling activation on fusions can render naive $\mathrm{T}$ cells refractory to suppression mediated by Tregs [88]. TLR ligands also activate DCs at the tumor site and enhance antigens cross-presentation, migration into regional lymph node, and induction of antigen-specific CTL responses $[87,89]$. Importantly, TLR ligands prevent the death of activation-induced CTLs by increasing the expression of antiapoptotic mediators (Bcl-xL and c-FLIP), allowing these cells to survive and migrate into the tumor site [90]. Moreover, the apoptosis of DCs can potentially regulate DCs homeostasis and immune responses. It has been reported that $\mathrm{Bim}$, a $\mathrm{BH} 3$ protein of the Bcl-2 family, is important for regulating spontaneous cell death of DCs [91]. Therefore, enhanced DCs/tumor fusions survival may play a role in efficient CTL inductions.

Another effective adjuvants for enhancing the induction of CD4+ and CD8+ T cells are HSPs, to which the ability of heat-treated tumor cells to enhance immunogenicity has been attributed [92]. Recently it has been shown that cross-priming is based on the transfer of proteasome substrates that are transcriptionally upregulated by heattreatment of tumor cells [29]. This is potentially important in the rational design for cancer vaccines that elicit CD8+ CTL responses. This concept offers additional effects by which heat treatment of tumor cells might enhance antigen-processing and -presentation in MHC class I and II molecules on the surfaces of DCs/tumor fusions. Moreover, extracellular HSPs act as a chaperon and interact with DCs in a receptor-mediated manner, leading to DCs maturation as well as proinflammatory responses, all of which are essential for induction of effective CD4+ and CD8+ CTL responses. Recently, we have shown that heat shock protein 70-peptide complexes (HSP70.PCs) derived from the DCs/tumor fusions possess superior properties compared with HSP70.PCs from tumor cells in animal and human models $[93,94]$. Namely, HSP70.PCs derived from human DCs/tumor fusions induced $\mathrm{T}$ cells that expressed higher levels of IFN- $\gamma$ and exhibited increased levels of killing of tumor cells, compared with those induced by HSP70.PCs derived from tumor cells. Enhanced immunogenicity of HSP70.PCs from DCs/tumor fusions was associated with improved composition of the vaccine, including increased content of TAAs and their processed intermediates, and the detection of other heat HSPs such as HSP90 and HSP110 [94].

\section{Induction of Antigen-Specific Polyclonal CTL Responses Restricted by MHC Class I and II Molecules}

Cancer vaccine approaches that rely on induction of immunity against particular antigens are potentially subject to tumor cell resistance mediated by the downregulation of the single antigen. Therefore, induction of polyclonal antigen-specific CTL responses may have the potential to maximize the protection against various subsets of tumor 
cells downregulated by certain tumor antigens, which may appear during the course of tumor progression. Fusions of DCs and autologous tumor cells are effective for induction of antigen-specific polyclonal CTL responses. How the fusions assemble and present the MHC class I-restricted multiple peptide complexes is unclear. One possibility is that multiple peptides are complexed with MHC class I molecules in tumor cells and the complexes are simply transferred to the fusion cells. Alternatively, the tumor cells may provide multiple tumor antigens and the fusion process simply facilitates the delivery of tumor antigens to the efficient antigen-processing and -presenting machinery in DCs. Then the tumor antigens are presented in the context of MHC class I and II molecules derived from DCs. We have demonstrated that fusions generated with allogeneic tumor cells and autologous DCs induced polyclonal antigen-specific CD4+ and CD8+ T cells restricted by autologous MHC class I and II molecules [95, 96]. These results suggest that the TAAs from allogeneic tumor cells are processed along the endogenous pathway, through the antigen-processing machinery of autologous DCs. Indeed, stimulation of $\mathrm{T}$ cells with fusions resulted in MHC class I and II restricted CD4+ and CD8+ T cell proliferation, high levels of IFN- $\gamma$ production in both $\mathrm{CD} 4+$ and $\mathrm{CD} 8+\mathrm{T}$ cells, and the simultaneous induction of polyclonal antigen-specific CTL responses restricted by multiple HLA molecules [84, 95-101].

\section{Generation of Tregs by DCs/Tumor Fusions}

Immature DCs are one of the mediators of tolerance induction. In peripheral lymphoid organs immature DCs are incapable of eliciting CTL responses. In contrast, if a stimulus for DCs activation is sufficiently coadministered with antigens, mature DCs express high levels of costimulatory molecules, resulting in priming of antigen-specific CTL induction rather than Tregs [86]. There are increasing evidences that tumor-derived soluble factors such as TGF- $\beta$ and IL-10 promote the induction of tolerance through the generation of CD4+ CD25high Foxp3+ Tregs, which may be linked to compromised immune responses in patients with cancer [102]. In animal models, tumor-derived TGF- $\beta$ reduces the efficacy of DCs/tumor fusion vaccine via in vivo mechanisms [42]. Moreover, the blockade of tumor-derived TGF- $\beta$ reduces Treg generation by the DCs/tumor fusions and enhances antitumor immunity [52]. Indeed, the potent immunosuppressive effects by Tregs can explain the failure of many immunotherapeutic approaches to patients with cancer [103]. In our study, fusions of immature DCs generated in the presence of tumor-derived culture supernatants promoted the generation of CD4+ CD25high Foxp3+ Tregs and inhibited CTL induction [88]. Recently, it has also been demonstrated that fusions in human are effective APCs to induce CTL responses but to stimulate inhibitory $\mathrm{T}$ cells that limit vaccine efficacy. However, exposure of DCs to TLR agonists, stimulatory cytokines, and anti-CD3/CD28 enhances vaccine efficacy by limiting the Treg responses and promoting expansion of CTLs in vitro [104]. Depletion of Tregs before vaccination may lead to enhanced CTL responses in cancer patients [103]. If the immune-suppressed environment in tumor is sufficiently improved, selective manipulation for the innate immune responses induced by TLR agonists may have more potential to promote DCs maturation and CTL over Treg generation [97]. As many tumors express or induce immunosuppressive cytokines such as IL-10 and TGF- $\beta$ in tumor environment, patients early in the course of the disease are expected to respond best to clinical responses by fusion cell vaccination. A combination of control of Tregs and concomitant induction of CTLs may be a more effective immunotherapy to reduce recurrence and prolong survival after surgery.

\section{Clinical Trials}

Based on these unique features of DCs/tumor fusions, initial Phase I/II clinical trials have been conducted in a variety of tumors (Table 1). Fusion cell vaccination has been reported in patients with melanoma $[98,99]$. In the report, autologous melanoma cells were fused to allogeneic DCs by electrofusion and assessed them as a vaccine in 17 patients with disseminated melanoma refractory to standard therapy. One patient had a partial response with decrease in size of all evaluable tumor manifestations. In one patient, some of the metastases were regressed despite overall progressive disease, and one patient achieved disease stabilization for 6 months. There were no serious side effects associated with the administration of the vaccine. In our initial clinical trial, 8 patients with malignant glioma were vaccinated with fusions of autologous DCs and autologous tumor cells. In all 6 cases analyzed, the concentration of IFN $-\gamma$ in the T cell culture supernatant increased after vaccination. However, clinical responses were not observed [101]. Therefore, we conducted a phase I/II clinical study for the safety profile of vaccination with DCs/tumor fusions combined with recombinant human (rh) IL-12 in patients with malignant brain tumor, melanoma, breast, gastric, colorectal, and ovarian cancer $[100,105]$. Eleven out of 15 patients with malignant brain tumor achieved a stable response and 24 patients had a progressive disease after 8 weeks of the initial treatment. The vaccine was well tolerated and no serious adverse effects were observed. In four patients, magnetic resonance imaging showed a greater than $50 \%$ reduction in tumor size. One patient had a mixed response. Therefore, coadministration of the fusions and rh IL-12 can induce more effective antitumor effects than fusions alone in some patients with malignant glioma. In this clinical trial, we vaccinated patients with extremely small amounts of fusion cells and rh IL-12 but resulted in immunological and clinical responses in a subset of patients with malignant brain tumor. The relatively favorable response to malignant brain tumors is of particular interesting since the central nervous system is generally considered to be an immunologically privileged site as a result of the lack of lymphatic drainage and the nature of the blood-brain barrier. However, these studies demonstrated that appropriately activated $\mathrm{T}$ cells could cross the blood-brain barrier to access the tumor burden and initiated tumor regression. On the other hand, 
TABLE 1: Assessment of DCs/tumor fusions based vaccine.

\begin{tabular}{|c|c|c|c|c|c|}
\hline \multirow{2}{*}{ Patients } & \multicolumn{2}{|c|}{ DCs/tumor fusions } & \multirow{2}{*}{ Coadministration } & \multirow{2}{*}{ Clinical responses } & \multirow{2}{*}{ Ref. } \\
\hline & Dendritic cells & Tumor cells & & & \\
\hline \multirow[t]{4}{*}{ Melanoma $(n=16)$} & Allogeneic & Autologous & & $1(\mathrm{CR})$ & {$[98]$} \\
\hline & & & & $1(\mathrm{PR})$ & \\
\hline & & & & $5(\mathrm{SD})$ & \\
\hline & & & & $9(\mathrm{PD})$ & \\
\hline \multirow[t]{3}{*}{ Glioma $(n=8)$} & Autologous & Autologous & & $2(\mathrm{PR})$ & [101] \\
\hline & & & & $1(\mathrm{SD})$ & \\
\hline & & & & $5(\mathrm{PD})$ & \\
\hline \multirow[t]{3}{*}{ Melanoma $(n=17)$} & Autologous & Autologous & & $1(\mathrm{PR})$ & {$[99]$} \\
\hline & & & & $1(\mathrm{SD})$ & \\
\hline & & & & $15(\mathrm{PD})$ & \\
\hline \multirow[t]{2}{*}{ Melanoma $(n=11)$} & Allogeneic & Autologous & rh IL-2 & $1(\mathrm{SD})$ & {$[100]$} \\
\hline & & & & $10(\mathrm{PD})$ & \\
\hline \multirow[t]{4}{*}{ Glioma $(n=12)$} & Autologous & Autologous & rh IL-12 & $3(\mathrm{PR})$ & {$[100]$} \\
\hline & & & & $2(\mathrm{MR})$ & \\
\hline & & & & $4(\mathrm{SD})$ & \\
\hline & & & & $3(\mathrm{PD})$ & \\
\hline \multirow[t]{2}{*}{ Breast cancer $(n=2)$} & Autologous & Autologous & rh IL-12 & $1(\mathrm{SD})$ & {$[100]$} \\
\hline & & & & $1(\mathrm{PD})$ & \\
\hline \multirow[t]{2}{*}{ Gastric/Colorectal cancer $(n=3)$} & Autologous & Autologous & rh IL-12 & $1(\mathrm{SD})$ & {$[100]$} \\
\hline & & & & $2(\mathrm{PD})$ & \\
\hline \multirow[t]{2}{*}{ Ovarian cancer $(n=3)$} & Autologous & Autologous & rh IL-12 & $2(\mathrm{SD})$ & {$[100]$} \\
\hline & & & & $1(\mathrm{PD})$ & \\
\hline Melanoma $(n=4)$ & Autologous & Autologous & rh IL-12 & $4(\mathrm{PD})$ & {$[100]$} \\
\hline \multirow[t]{3}{*}{ Breast cancer $(n=10)$} & Autologous & Autologous & & $2(\mathrm{PR})$ & {$[21]$} \\
\hline & & & & $1(\mathrm{SD})$ & \\
\hline & & & & $7(\mathrm{PD})$ & \\
\hline \multirow[t]{3}{*}{ Renal cell carcinoma $(n=20)$} & Allogeneic & Autologous & & $2(\mathrm{PR})$ & {$[22]$} \\
\hline & & & & $8(\mathrm{SD})$ & \\
\hline & & & & $10(\mathrm{PD})$ & \\
\hline Hepatocellular carcinoma $(n=1)$ & Autologous & Autologous & & $1(\mathrm{PD})$ & {$[88]$} \\
\hline
\end{tabular}

CR: complete response; PR: partial response; MR: mixed response; SD: stable disease; PD: progressive disease.

patients with metastatic breast or renal cancer were also treated with fusions of autologous DCs and autologous tumor cells [21]. In this trial, 23 patients were vaccinated by the fusions and no significant treatment-related toxicity was observed. In a subset of patients, vaccination resulted in immunological responses. Interestingly, 2 patients with breast cancer exhibited disease regressions, including a near complete response of a large chest wall mass. Five patients with renal carcinoma and one patient with breast cancer had disease stabilization. Recently, this group evaluated the effect of vaccination with fusions of allogeneic DCs and autologous tumor cells in patients with stage IV renal cell carcinoma [22]. Vaccination of the fusions resulted in antitumor immune responses in $10(48 \%)$ of 21 evaluable patients. Two out of 21 patients demonstrated a partial clinical response and 8 patients had stabilization of their disease. In clinical trials, only limited therapeutic results were obtained; however, DCs/tumor fusions-based vaccine may work more effectively in patients in the early stage of the disease with low tumor burden after surgery, chemotherapy, or irradiation.

In the clinical setting of the patients with cancer, a major difficulty for the fusions vaccine is the preparation of sufficient amounts of autologous tumor cells. The specimen of tumor from primary lesion may not provide sufficient numbers of viable tumor cells due to the length of culture time and potential contamination of bacteria and fungus. We have reported that fusions of autologous DCs and allogeneic tumor cell lines induced CTL responses against the autologous tumor cells $[95,96]$. The basis for using allogeneic tumor cell lines instead of autologous tumor cells is that some antigens are shared by most of tumors. 
This strategy has numerous advantages. (a) Allogeneic tumor cell lines are well characterized as TAA source. (b) Allogeneic tumor cell lines, which share with TAAs, can grow well in vitro; thus, there is no limiting factor for preparation of tumor cells. (c) It is not necessary to determine HLA typing of patients and allogeneic tumor cells as a partner of fusion cells, because autologous DCs can process and present multiple TAAs from allogeneic tumor cells in the context of MHC class I and class II molecules. The clinical trials using allogeneic fusions have not been reported yet.

\section{Future Directions}

Although fusion cell vaccination is effective to induce CTL responses, we are searching for optimal strategy to benefit patients significantly. DCs/tumor fusion cell vaccine alone may be insufficient to have a significant contribution to treat advanced cancer patients with compromised immune system. To elicite polyclonal CTL induction in patients with cancer, it may be necessary to combine with chemotherapy, radiotherapy, hormonal therapy, or photodynamic therapy to reduce Treg and enhance CTL responses. Indeed, the combination therapy of fusion cell vaccination and adoptive immunotherapy is a very effective against poorly immunogenic carcinomas in murine studies [41, 53, 106]. Combination with these approaches has enormous potential to improve the current outcomes from conventional cancer therapy. The next decade will see the first clinical trials testing whether combination of induction of augmented CTLs and depletion of Tregs might be effective in treatment for cancer patients.

\section{Acknowledgment}

This work has been supported by Grants-in-Aid for Scientific Research (B and C) from the Ministry of Education, Cultures, Sports, Science and Technology of Japan, Grantin-Aid of the Japan Medical Association, Takeda Science Foundation, Pancreas Research Foundation of Japan, The Promotion and Mutual Aid Corporation for Private School of Japan and Foundation for Promotion of Cancer Research.

\section{References}

[1] R. M. Steinman and J. Banchereau, "Taking dendritic cells into medicine," Nature, vol. 449, no. 7161, pp. 419-426, 2007.

[2] J. Banchereau and A. K. Palucka, "Dendritic cells as therapeutic vaccines against cancer," Nature Reviews Immunology, vol. 5, no. 4, pp. 296-306, 2005.

[3] J. Banchereau and R. M. Steinman, "Dendritic cells and the control of immunity," Nature, vol. 392, no. 6673, pp. 245252, 1998.

[4] A. Mackensen, B. Herbst, J.-L. Chen, et al., "Phase I study in melanoma patients of a vaccine with peptide-pulsed dendritic cells generated in vitro from $\mathrm{CD} 34^{+}$hematopoietic progenitor cells," International Journal of Cancer, vol. 89, no. 2, pp. 385-392, 2000.
[5] B. Thurner, I. Haendle, C. Roder, et al., "Vaccination with Mage-3A1 peptide-pulsed nature, monocyte-derived dendritic cells expands specific cytotoxic $\mathrm{T}$ cells and induces regression of some metastases in advanced stage IV melanoma," Journal of Experimental Medicine, vol. 190, no. 11, pp. 1669-1678, 1999.

[6] C. M. Celluzzi, J. I. Mayordomo, W. J. Storkus, M. T. Lotze, and L. D. Falo Jr., "Peptide-pulsed dendritic cells induce antigen-specific, CTL-mediated protective tumor immunity," Journal of Experimental Medicine, vol. 183, no. 1, pp. 283-287, 1996.

[7] F. O. Nestle, S. Alijagic, M. Gilliet, et al., "Vaccination of melanoma patients with peptide- or tumor lysate-pulsed dendritic cells," Nature Medicine, vol. 4, no. 3, pp. 328-332, 1998.

[8] J. I. Mayordomo, T. Zorina, W. J. Storkus, et al., "Bone marrow-derived dendritic cells pulsed with synthetic tumour peptides elicit protective and therapeutic antitumour immunity," Nature Medicine, vol. 1, no. 12, pp. 1297-1302, 1995.

[9] J. Gong, L. Chen, D. Chen, et al., "Induction of antigenspecific antitumor immunity with adenovirus-transduced dendritic cells," Gene Therapy, vol. 4, no. 10, pp. 1023-1028, 1997.

[10] S. Koido, M. Kashiwaba, D. Chen, S. Gendler, D. Kufe, and J. Gong, "Induction of antitumor immunity by vaccination of dendritic cells transfected with MUC1 RNA," The Journal of Immunology, vol. 165, no. 10, pp. 5713-5719, 2000.

[11] K. Shimizu, H. Kuriyama, J. Kjaergaard, W. Lee, H. Tanaka, and S. Shu, "Comparative analysis of antigen loading strategies of dendritic cells for tumor immunotherapy," Journal of Immunotherapy, vol. 27, no. 4, pp. 265-272, 2004.

[12] J. Gong, D. Chen, M. Kashiwaba, and D. Kufe, "Induction of antitumor activity by immunization with fusions of dendritic and carcinoma cells," Nature Medicine, vol. 3, no. 5, pp. 558561, 1997.

[13] J. Gong, S. Koido, and S. K. Calderwood, "Cell fusion: from hybridoma to dendritic cell-based vaccine," Expert Review of Vaccines, vol. 7, no. 7, pp. 1055-1068, 2008.

[14] S. Koido, E. Hara, S. Homma, K. Fujise, J. Gong, and H. Tajiri, "Dendritic/tumor fusion cell-based vaccination against cancer," Archivum Immunologiae et Therapiae Experimentalis, vol. 55, no. 5, pp. 281-287, 2007.

[15] S. Koido, E. Hara, S. Homma, T. Ohkusa, J. Gong, and H. Tajiri, "Cancer immunotherapy by fusions of dendritic cells and tumor cells," Immunotherapy, vol. 1, no. 1, pp. 49-62, 2009.

[16] H. Tanaka, K. Shimizu, T. Hayashi, and S. Shu, "Therapeutic immune response induced by electrofusion of dendritic and tumor cells," Cellular Immunology, vol. 220, no. 1, pp. 1-12, 2002.

[17] K. Hiraoka, S. Yamamoto, S. Otsuru, et al., "Enhanced tumor-specific long-term immunity of hemagglutinating virus of Japan-mediated dendritic cell-tumor fused cell vaccination by coadministration with $\mathrm{CpG}$ oligodeoxynucleotides," The Journal of Immunology, vol. 173, no. 7, pp. 4297-4307, 2004.

[18] S. Koido, E. Hara, S. Homma, et al., "Streptococcal preparation OK-432 promotes fusion efficiency and enhances induction of antigen-specific CTL by fusions of dendritic cells and colorectal cancer cells," The Journal of Immunology, vol. 178, no. 1, pp. 613-622, 2007.

[19] J. Li, L. M. Holmes, K. J. Franek, K. E. Burgin, T. E. Wagner, and Y. Wei, "Purified hybrid cells from dendritic cell and tumor cell fusions are superior activators of antitumor 
immunity," Cancer Immunology, Immunotherapy, vol. 50, no. 9, pp. 456-462, 2001.

[20] T. Suzuki, T. Fukuhara, M. Tanaka, et al., "Vaccination of dendritic cells loaded with interleukin-12-secreting cancer cells augments in vivo antitumor immunity: characteristics of syngeneic and allogeneic antigen-presenting cell cancer hybrid cells," Clinical Cancer Research, vol. 11, no. 1, pp. 5866, 2005.

[21] D. Avigan, B. Vasir, J. Gong, et al., "Fusion cell vaccination of patients with metastatic breast and renal cancer induces immunological and clinical responses," Clinical Cancer Research, vol. 10, no. 14, pp. 4699-4708, 2004.

[22] D. E. Avigan, B. Vasir, D. J. George, et al., "Phase I/II study of vaccination with electrofused allogeneic dendritic cells/autologous tumor-derived cells in patients with stage IV renal cell carcinoma," Journal of Immunotherapy, vol. 30, no. 7, pp. 749-761, 2007.

[23] M. C. Wolkers, N. Brouwenstijn, A. H. Bakker, M. Toebes, and T. N. M. Schumacher, "Antigen bias in T cell crosspriming," Science, vol. 304, no. 5675, pp. 1314-1317, 2004.

[24] J. Wang, S. Saffold, X. Cao, J. Krauss, and W. Chen, "Eliciting $\mathrm{T}$ cell immunity against poorly immunogenic tumors by immunization with dendritic cell-tumor fusion vaccines," The Journal of Immunology, vol. 161, no. 10, pp. 5516-5524, 1998.

[25] F. Benencia, M. C. Courreges, and G. Coukos, "Whole tumor antigen vaccination using dendritic cells: comparison of RNA electroporation and pulsing with UV-irradiated tumor cells," Journal of Translational Medicine, vol. 6, article 21, 2008.

[26] S. Shu, R. Zheng, W. T. Lee, and P. A. Cohen, "Immunogenicity of dendritic-tumor fusion hybrids and their utility in cancer immunotherapy," Critical Reviews in Immunology, vol. 27, no. 5, pp. 463-483, 2007.

[27] S. Koido, M. Ohana, C. Liu, et al., "Dendritic cells fused with human cancer cells: morphology, antigen expression, and $\mathrm{T}$ cell stimulation," Clinical Immunology, vol. 113, no. 3, pp. 261-269, 2004.

[28] M. Okamoto, S. Furuichi, Y. Nishioka, et al., "Expression of toll-like receptor 4 on dendritic cells is significant for anticancer effect of dendritic cell-based immunotherapy in combination with active component of OK-432, a streptococcal preparation," Cancer Research, vol. 64, no. 15, pp. 5461-5470, 2004.

[29] C. C. Norbury, S. Basta, K. B. Donohue, et al., "CD8 ${ }^{+}$T cell cross-priming via transfer of proteasome substrates," Science, vol. 304, no. 5675, pp. 1318-1321, 2004.

[30] S. Koido, E. Hara, S. Homma, et al., "Synergistic induction of antigen-specific CTL by fusions of TLR-stimulated dendritic cells and heat-stressed tumor cells," The Journal of Immunology, vol. 179, no. 7, pp. 4874-4883, 2007.

[31] S. Patton, S. J. Gendler, and A. P. Spicer, "The epithelial mucin, MUC1, of milk, mammary gland and other tissues," Biochimica et Biophysica Acta, vol. 1241, no. 3, pp. 407-423, 1995.

[32] G. J. Rowse, R. M. Tempero, M. L. VanLith, M. A. Hollingsworth, and S. J. Gendler, "Tolerance and immunity to MUC1 in a human MUC1 transgenic murine model," Cancer Research, vol. 58, no. 2, pp. 315-321, 1998.

[33] J. Gong, D. Chen, M. Kashiwaba, et al., "Reversal of tolerance to human MUC1 antigen in MUC1 transgenic mice immunized with fusions of dendritic and carcinoma cells," Proceedings of the National Academy of Sciences of the United States of America, vol. 95, no. 11, pp. 6279-6283, 1998.
[34] S. Koido, Y. Tanaka, D. Chen, D. Kufe, and J. Gong, "The kinetics of in vivo priming of CD4 and CD8 T cells by dendritic/tumor fusion cells in MUC1-transgenic mice," The Journal of Immunology, vol. 168, no. 5, pp. 2111-2117, 2002.

[35] Y. Tanaka, S. Koido, D. Chen, S. J. Gendler, D. Kufe, and J. Gong, "Vaccination with allogeneic dendritic cells fused to carcinoma cells induces antitumor immunity in MUC1 transgenic mice," Clinical Immunology, vol. 101, no. 2, pp. 192-200, 2001.

[36] X. Cao, W. Zhang, J. Wang, et al., “Therapy of established tumour with a hybrid cellular vaccine generated by using granulocyte-macrophage colony-stimulating factor genetically modified dendritic cells," Immunology, vol. 97, no. 4, pp. 616-625, 1999.

[37] S. Salomskaite-Davalgiene, K. Cepurniene, S. Satkauskas, M. S. Venslauskas, and L. M. Mir, "Extent of cell electrofusion in vitro and in vivo is cell line dependent," Anticancer Research, vol. 29, no. 8, pp. 3125-3130, 2009.

[38] R. Zheng, P. A. Cohen, C. A. Paustian, et al., "Paired toll-like receptor agonists enhance vaccine therapy through induction of interleukin-12," Cancer Research, vol. 68, no. 11, pp. 40454049, 2008.

[39] H. Kuriyama, S. Watanabe, J. Kjaergaard, et al., "Mechanism of third signals provided by IL- 12 and OX-40R ligation in eliciting therapeutic immunity following dendritic-tumor fusion vaccination," Cellular Immunology, vol. 243, no. 1, pp. 30-40, 2006.

[40] V. Phan, F. Errington, S. C. Cheong, et al., "A new genetic method to generate and isolate small, short-lived but highly potent dendritic cell-tumor cell hybrid vaccines," Nature Medicine, vol. 9, no. 9, pp. 1215-1219, 2003.

[41] J. Gong, V. Apostolopoulos, D. Chen, et al., "Selection and characterization of MUC1-specific CD8 ${ }^{+} \mathrm{T}$ cells from MUC1 transgenic mice immunized with dendritic-carcinoma fusion cells," Immunology, vol. 101, no. 3, pp. 316-324, 2000.

[42] J. Y. Kao, Y. Gong, C.-M. Chen, Q.-D. Zheng, and J.-J. Chen, "Tumor-derived TGF- $\beta$ reduces the efficacy of dendritic cell/tumor fusion vaccine," The Journal of Immunology, vol. 170, no. 7, pp. 3806-3811, 2003.

[43] T. Iinuma, S. Homma, T. Noda, D. Kufe, T. Ohno, and G. Toda, "Prevention of gastrointestinal tumors based on adenomatous polyposis coli gene mutation by dendritic cell vaccine," Journal of Clinical Investigation, vol. 113, no. 9, pp. 1307-1317, 2004.

[44] J. Y. Kao, M. Zhang, C.-M. Chen, and J.-J. Chen, "Superior efficacy of dendritic cell-tumor fusion vaccine compared with tumor lysate-pulsed dendritic cell vaccine in colon cancer," Immunology Letters, vol. 101, no. 2, pp. 154-159, 2005.

[45] F. Xu, Y.-J. Ye, Z.-R. Cui, and S. Wang, "Allogeneic dendritomas induce anti-tumour immunity against metastatic colon cancer," Scandinavian Journal of Immunology, vol. 61, no. 4, pp. 364-369, 2005.

[46] T. Yasuda, T. Kamigaki, T. Nakamura, et al., "Dendritic celltumor cell hybrids enhance the induction of cytotoxic $\mathrm{T}$ lymphocytes against murine colon cancer: a comparative analysis of antigen loading methods for the vaccination of immunotherapeutic dendritic cells," Oncology Reports, vol. 16, no. 6, pp. 1317-1324, 2006.

[47] T. Yasuda, T. Kamigaki, K. Kawasaki, et al., "Superior antitumor protection and therapeutic efficacy of vaccination with allogeneic and semiallogeneic dendritic cell/tumor cell 
fusion hybrids for murine colon adenocarcinoma," Cancer Immunology, Immunotherapy, vol. 56, no. 7, pp. 1025-1036, 2007.

[48] A. Ishida, H. Tanaka, T. Hiura, et al., "Generation of antitumour effector $\mathrm{T}$ cells from naive $\mathrm{T}$ cells by stimulation with dendritic/tumour fusion cells," Scandinavian Journal of Immunology, vol. 66, no. 5, pp. 546-554, 2007.

[49] J. Gong, D. Avigan, D. Chen, et al., "Activation of antitumor cytotoxic $\mathrm{T}$ lymphocytes by fusions of human dendritic cells and breast carcinoma cells," Proceedings of the National Academy of Sciences of the United States of America, vol. 97, no. 6, pp. 2715-2718, 2000.

[50] J. Xia, Y. Tanaka, S. Koido, et al., "Prevention of spontaneous breast carcinoma by prophylactic vaccination with dendritic/tumor fusion cells," The Journal of Immunology, vol. 170, no. 4, pp. 1980-1986, 2003.

[51] D. Chen, J. Xia, Y. Tanaka, et al., "Immunotherapy of spontaneous mammary carcinoma with fusions of dendritic cells and mucin 1-positive carcinoma cells," Immunology, vol. 109, no. 2, pp. 300-307, 2003.

[52] M. Zhang, B. E. Berndt, J. J. Chen, and J. Y. Kao, "Expression of a soluble TGF-beta receptor by tumor cells enhances dendritic cell/tumor fusion vaccine efficacy," The Journal of Immunology, vol. 181, no. 5, pp. 3690-3697, 2008.

[53] H. Tamai, S. Watanabe, R. Zheng, et al., "Effective treatment of spontaneous metastases derived from a poorly immunogenic murine mammary carcinoma by combined dendritictumor hybrid vaccination and adoptive transfer of sensitized T cells," Clinical Immunology, vol. 127, no. 1, pp. 66-77, 2008.

[54] G.-H. Guo, S.-Z. Chen, J. Yu, et al., "In vivo anti-tumor effect of hybrid vaccine of dendritic cells and esophageal carcinoma cells on esophageal carcinoma cell line 109 in mice with severe combined immune deficiency," World Journal of Gastroenterology, vol. 14, no. 8, pp. 1167-1174, 2008.

[55] M. Yamamoto, T. Kamigaki, K. Yamashita, et al., "Enhancement of anti-tumor immunity by high levels of Th1 and Th17 with a combination of dendritic cell fusion hybrids and regulatory T cell depletion in pancreatic cancer," Oncology Reports, vol. 22, no. 2, pp. 337-343, 2009.

[56] S. Homma, G. Toda, J. Gong, D. Kufe, and T. Ohno, "Preventive antitumor activity against hepatocellular carcinoma (HCC) induced by immunization with fusions of dendritic cells and HCC cells in mice," Journal of Gastroenterology, vol. 36, no. 11, pp. 764-771, 2001.

[57] J.-K. Zhang, J. Li, J. Zhang, H.-B. Chen, and S.-B. Chen, "Antitumor immunopreventive and immunotherapeutic effect in mice induced by hybrid vaccine of dendritic cells and hepatocarcinoma in vivo," World Journal of Gastroenterology, vol. 9, no. 3, pp. 479-484, 2003.

[58] M. Iriei, S. Homma, H. Komita, et al., "Inhibition of spontaneous development of liver tumors by inoculation with dendritic cells loaded with hepatocellular carcinoma cells in C3H/HeNCRJ mice," International Journal of Cancer, vol. 111, no. 2, pp. 238-245, 2004.

[59] H.-M. Zhang, L.-W. Zhang, W.-C. Liu, J. Cheng, X.-M. Si, and J. Ren, "Comparative analysis of DC fused with tumor cells or transfected with tumor total RNA as potential cancer vaccines against hepatocellular carcinoma," Cytotherapy, vol. 8, no. 6, pp. 580-588, 2006.

[60] X.-L. Sheng and H. Zhang, "In-vitro activation of cytotoxic T lymphocytes by fusion of mouse hepatocellular carcinoma cells and lymphotactin gene-modified dendritic cells," World Journal of Gastroenterology, vol. 13, no. 44, pp. 5944-5950, 2007.
[61] C. M. Celluzzi and L. D. Falo Jr., "Physical interaction between dendritic cells and tumor cells results in an immunogen that induces protective and therapeutic tumor rejection," The Journal of Immunology, vol. 160, no. 7, pp. 3081-3085, 1998.

[62] R. Savai, R. T. Schermuly, M. Schneider, et al., "Hybridprimed lymphocytes and hybrid vaccination prevent tumor growth of Lewis lung carcinoma in mice," Journal of Immunotherapy, vol. 29, no. 2, pp. 175-187, 2006.

[63] J. B. Weise, S. Maune, T. Gorogh, et al., "A dendritic cell based hybrid cell vaccine generated by electrofusion for immunotherapy strategies in HNSCC," Auris Nasus Larynx, vol. 31, no. 2, pp. 149-153, 2004.

[64] W. M. Siders, K. L. Vergilis, C. Johnson, J. Shields, and J. M. Kaplan, "Induction of specific antitumor immunity in the mouse with the electrofusion product of tumor cells and dendritic cells," Molecular Therapy, vol. 7, no. 4, pp. 498-505, 2003.

[65] J. Kjaergaard, K. Shimizu, and S. Shu, "Electrofusion of syngeneic dendritic cells and tumor generates potent therapeutic vaccine," Cellular Immunology, vol. 225, no. 2, pp. 65-74, 2003.

[66] W. Guo, Y. Guo, S. Tang, H. Qu, and H. Zhao, "Dendritic cellEwing's sarcoma cell hybrids enhance antitumor immunity," Clinical Orthopaedics and Related Research, vol. 466, no. 9, pp. 2176-2183, 2008.

[67] H. Matsue, K. Matsue, D. Edelbaum, M. Walters, A. Morita, and A. Takashima, "New strategy for efficient selection of dendritic cell-tumor hybrids and clonal heterogeneity of resulting hybrids," Cancer Biology and Therapy, vol. 3, no. 11, pp. 1145-1151, 2004.

[68] J. Gong, S. Koido, D. Chen, et al., "Immunization against murine multiple myeloma with fusions of dendritic and plasmacytoma cells is potentiated by interleukin 12," Blood, vol. 99, no. 7, pp. 2512-2517, 2002.

[69] Y. Liu, W. Zhang, T. Chan, A. Saxena, and J. Xiang, "Engineered fusion hybrid vaccine of IL-4 gene-modified myeloma and relative mature dendritic cells enhances antitumor immunity," Leukemia Research, vol. 26, no. 8, pp. 757-763, 2002.

[70] S. Hao, X. Bi, S. Xu, et al., "Enhanced antitumor immunity derived from a novel vaccine of fusion hybrid between dendritic and engineered myeloma cells," Experimental Oncology, vol. 26, no. 4, pp. 300-306, 2004.

[71] M. Shi, L. Su, S. Hao, X. Guo, and J. Xiang, "Fusion hybrid of dendritic cells and engineered tumor cells expressing interleukin-12 induces type 1 immune responses against tumor," Tumori, vol. 91, no. 6, pp. 531-538, 2005.

[72] S. Queant, C.-O. Sarde, M.-G. Gobert, J. Kadouche, and A. Roseto, "Antitumor response against myeloma cells by immunization with mouse syngenic dendritoma," Hybridoma, vol. 24, no. 4, pp. 182-188, 2005.

[73] D. Xia, F. Li, and J. Xiang, "Engineered fusion hybrid vaccine of IL-18 gene-modified tumor cells and dendritic cells induces enhanced antitumor immunity," Cancer Biotherapy and Radiopharmaceuticals, vol. 19, no. 3, pp. 322-330, 2004.

[74] L. Lespagnard, P. Mettens, A.-M. Verheyden, et al., "Dendritic cells fused with mastocytoma cells elicit therapeutic antitumor immunity," International Journal of Cancer, vol. 76, no. 2, pp. 250-258, 1998.

[75] H. Iinuma, K. Okinaga, R. Fukushima, et al., "Superior protective and therapeutic effects of IL-12 and IL-18 gene-transduced dendritic neuroblastoma fusion cells on 
liver metastasis of murine neuroblastoma," The Journal of Immunology, vol. 176, no. 6, pp. 3461-3469, 2006.

[76] C. T. Guy, R. D. Cardiff, and W. J. Muller, "Induction of mammary tumors by expression of polyomavirus middle $\mathrm{T}$ oncogene: a transgenic mouse model for metastatic disease," Molecular and Cellular Biology, vol. 12, no. 3, pp. 954-961, 1992.

[77] Y. Tanaka, S. Koido, M. Ohana, C. Liu, and J. Gong, "Induction of impaired antitumor immunity by fusion of MHC class II-deficient dendritic cells with tumor cells," The Journal of Immunology, vol. 174, no. 3, pp. 1274-1280, 2005.

[78] R. E. M. Toes, F. Ossendorp, R. Offringa, and C. J. M. Melief, "CD4 T cells and their role in antitumor immune responses," Journal of Experimental Medicine, vol. 189, no. 5, pp. 753756, 1999.

[79] S. P. Schoenberger, R. E. M. Toes, E. I. H. van der Voort, R. Offringa, and C. J. M. Melief, "T-cell help for cytotoxic T lymphocytes is mediated by CD40-CD40L interactions," Nature, vol. 393, no. 6684, pp. 480-483, 1998.

[80] E. R. Fearon, D. M. Pardoll, T. Itaya, et al., "Interleukin-2 production by tumor cells bypasses $\mathrm{T}$ helper function in the generation of an antitumor response," Cell, vol. 60, no. 3, pp. 397-403, 1990.

[81] K. Hung, R. Hayashi, A. Lafond-Walker, C. Lowenstein, D. Pardoll, and H. Levitsky, "The central role of CD4 ${ }^{+} \mathrm{T}$ cells in the antitumor immune response," Journal of Experimental Medicine, vol. 188, no. 12, pp. 2357-2368, 1998.

[82] K. Schepers, M. Toebes, G. Sotthewes, et al., "Differential kinetics of antigen-specific $\mathrm{CD}^{+}$and $\mathrm{CD} 8^{+} \mathrm{T}$ cell responses in the regression of retrovirus-induced sarcomas," The Journal of Immunology, vol. 169, no. 6, pp. 3191-3199, 2002.

[83] F. Ossendorp, E. Mengede, M. Camps, R. Filius, and C. J. M. Melief, "Specific T helper cell requirement for optimal induction of cytotoxic T lymphocytes against major histocompatibility complex class II negative tumors," Journal of Experimental Medicine, vol. 187, no. 5, pp. 693-702, 1998.

[84] S. Koido, E. Hara, A. Torii, et al., "Induction of antigenspecific CD4- and CD8-mediated T-cell responses by fusions of autologous dendritic cells and metastatic colorectal cancer cells," International Journal of Cancer, vol. 117, no. 4, pp. 587595, 2005.

[85] S. R. M. Bennett, F. R. Carbone, F. Karamalis, J. F. A. P. Miller, and W. R. Heath, "Induction of a $\mathrm{CD}^{+}$cytotoxic $\mathrm{T}$ lymphocyte response by cross-priming requires cognate $\mathrm{CD}^{+} \mathrm{T}$ cell help," Journal of Experimental Medicine, vol. 186, no. 1, pp. 65-70, 1997.

[86] W. R. Heath and F. R. Carbone, "Cross-presentation in viral immunity and self-tolerance," Nature Reviews Immunology, vol. 1, no. 2, pp. 126-134, 2001.

[87] E. Celis, "Toll-like receptor ligands energize peptide vaccines through multiple paths," Cancer Research, vol. 67, no. 17, pp. 7945-7947, 2007.

[88] S. Koido, S. Homma, E. Hara, et al., "In vitro generation of cytotoxic and regulatory $\mathrm{T}$ cells by fusions of human dendritic cells and hepatocellular carcinoma cells," Journal of Translational Medicine, vol. 6, article 51, 2008.

[89] R.-F. Wang, "Regulatory $\mathrm{T}$ cells and toll-like receptors in cancer therapy," Cancer Research, vol. 66, no. 10, pp. 49874990, 2006.

[90] R.-F. Wang, Y. Miyahara, and H. Y. Wang, "Toll-like receptors and immune regulation: implications for cancer therapy," Oncogene, vol. 27, no. 2, pp. 181-189, 2008.
[91] M. Chen, L. Huang, and J. Wang, "Deficiency of Bim in dendritic cells contributes to overactivation of lymphocytes and autoimmunity," Blood, vol. 109, no. 10, pp. 4360-4367, 2007.

[92] Y. Tamura, P. Peng, K. Liu, M. Daou, and P. K. Srivastava, "Immunotherapy of tumors with autologous tumor-derived heat shock protein preparations," Science, vol. 278, no. 5335, pp. 117-120, 1997.

[93] Y. Enomoto, A. Bharti, A. A. Khaleque, et al., "Enhanced immunogenicity of heat shock protein 70 peptide complexes from dendritic cell-tumor fusion cells," The Journal of Immunology, vol. 177, no. 9, pp. 5946-5955, 2006.

[94] J. Gong, Y. Zhang, J. Durfee, et al., "A heat shock protein 70-based vaccine with enhanced immunogenicity for clinical use," The Journal of Immunology, vol. 184, no. 1, pp. 488-496, 2010.

[95] S. Koido, E. Hara, S. Homma, et al., "Dendritic cells fused with allogeneic colorectal cancer cell line present multiple colorectal cancer-specific antigens and induce antitumor immunity against autologous tumor cells," Clinical Cancer Research, vol. 11, no. 21, pp. 7891-7900, 2005.

[96] S. Koido, Y. Tanaka, H. Tajiri, and J. Gong, "Generation and functional assessment of antigen-specific T cells stimulated by fusions of dendritic cells and allogeneic breast cancer cells," Vaccine, vol. 25, no. 14, pp. 2610-2619, 2007.

[97] A. R. Neves, L. F. C. Ensina, L. B. Anselmo, et al., "Dendritic cells derived from metastatic cancer patients vaccinated with allogeneic dendritic cell-autologous tumor cell hybrids express more CD86 and induce higher levels of interferongamma in mixed lymphocyte reactions," Cancer Immunology, Immunotherapy, vol. 54, no. 1, pp. 61-66, 2005.

[98] U. Trefzer, G. Herberth, K. Wohlan, et al., "Tumour-dendritic hybrid cell vaccination for the treatment of patients with malignant melanoma: immunological effects and clinical results," Vaccine, vol. 23, no. 17-18, pp. 2367-2373, 2005.

[99] U. Trefzer, G. Weingart, Y. Chen, et al., "Hybrid cell vaccination for cancer immune therapy: first clinical trial with metastatic melanoma," International Journal of Cancer, vol. 85, no. 5, pp. 618-626, 2000.

[100] T. Kikuchi, Y. Akasaki, T. Abe, et al., "Vaccination of glioma patients with fusions of dendritic and glioma cells and recombinant human interleukin 12," Journal of Immunotherapy, vol. 27, no. 6, pp. 452-459, 2004.

[101] T. Kikuchi, Y. Akasaki, M. Irie, S. Homma, T. Abe, and T. Ohno, "Results of a phase I clinical trial of vaccination of glioma patients with fusions of dendritic and glioma cells," Cancer Immunology, Immunotherapy, vol. 50, no. 7, pp. 337344, 2001.

[102] J. Fu, D. Xu, Z. Liu, et al., "Increased regulatory T cells correlate with CD8 T-cell impairment and poor survival in hepatocellular carcinoma patients," Gastroenterology, vol. 132, no. 7, pp. 2328-2339, 2007.

[103] M. A. Morse, A. C. Hobeika, T. Osada, et al., "Depletion of human regulatory $\mathrm{T}$ cells specifically enhances antigenspecific immune responses to cancer vaccines," Blood, vol. 112, no. 3, pp. 610-618, 2008.

[104] B. Vasir, Z. Wu, K. Crawford, et al., "Fusions of dendritic cells with breast carcinoma stimulate the expansion of regulatory T cells while concomitant exposure to IL-12, CpG oligodeoxynucleotides, and anti-CD3/CD28 promotes the expansion of activated tumor reactive cells," The Journal of Immunology, vol. 181, no. 1, pp. 808-821, 2008. 
[105] S. Homma, Y. Sagawa, M. Ito, T. Ohno, and G. Toda, "Cancer immunotherapy using dendritic/tumour-fusion vaccine induces elevation of serum anti-nuclear antibody with better clinical responses," Clinical and Experimental Immunology, vol. 144, no. 1, pp. 41-47, 2006.

[106] R. Savai, R. T. Schermuly, S. S. Pullamsetti, et al., "A combination hybrid-based vaccination/adoptive cellular therapy to prevent tumor growth by involvement of T cells," Cancer Research, vol. 67, no. 11, pp. 5443-5453, 2007. 


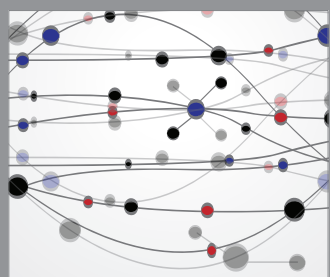

The Scientific World Journal
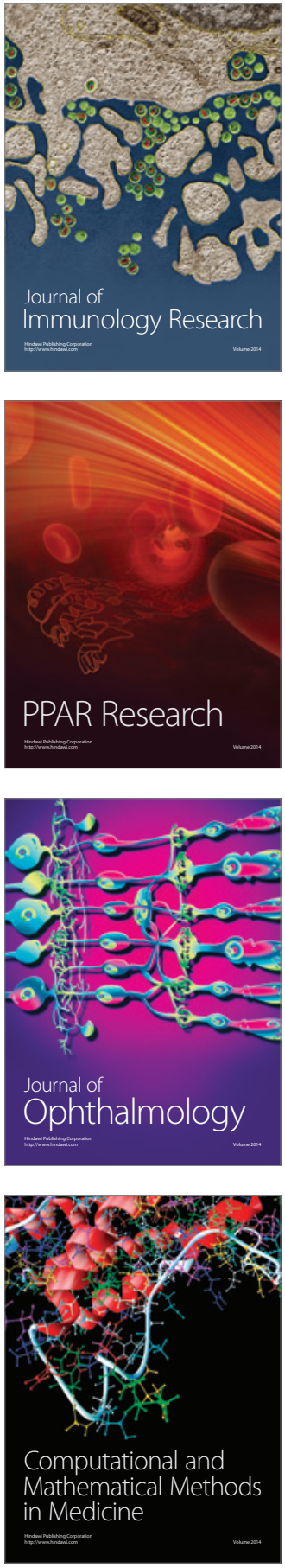

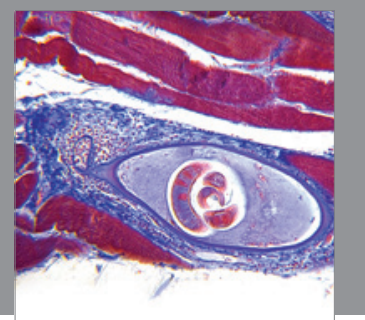

Gastroenterology

Research and Practice
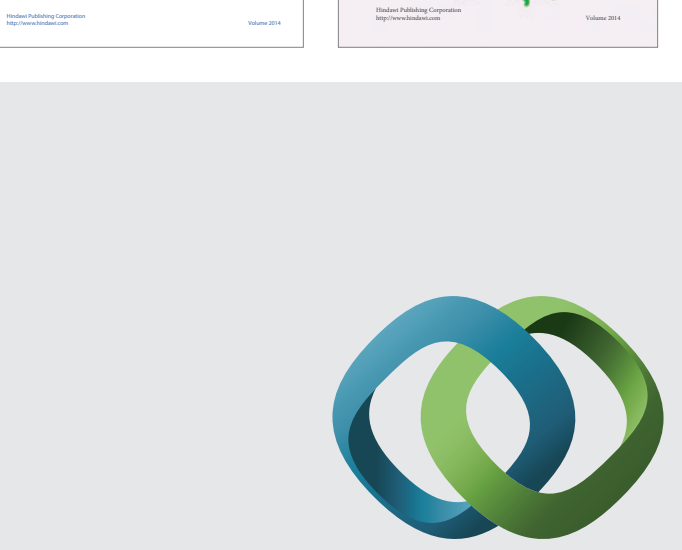

\section{Hindawi}

Submit your manuscripts at

http://www.hindawi.com
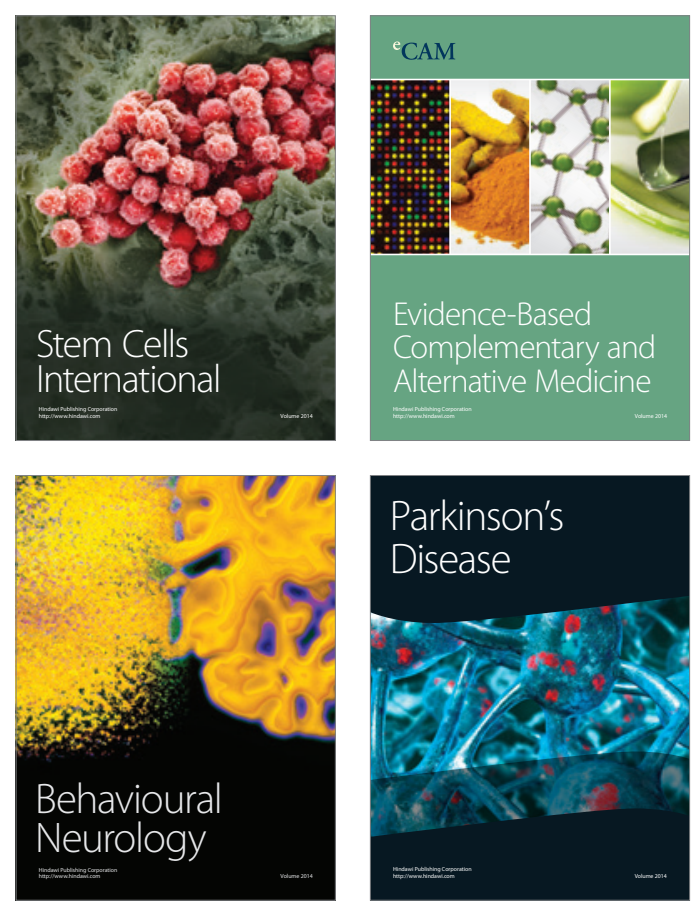

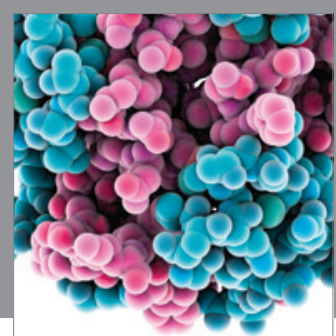

Journal of
Diabetes Research

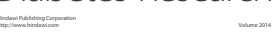

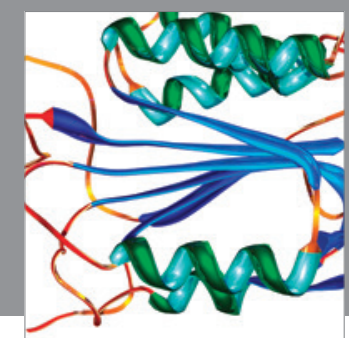

Disease Markers
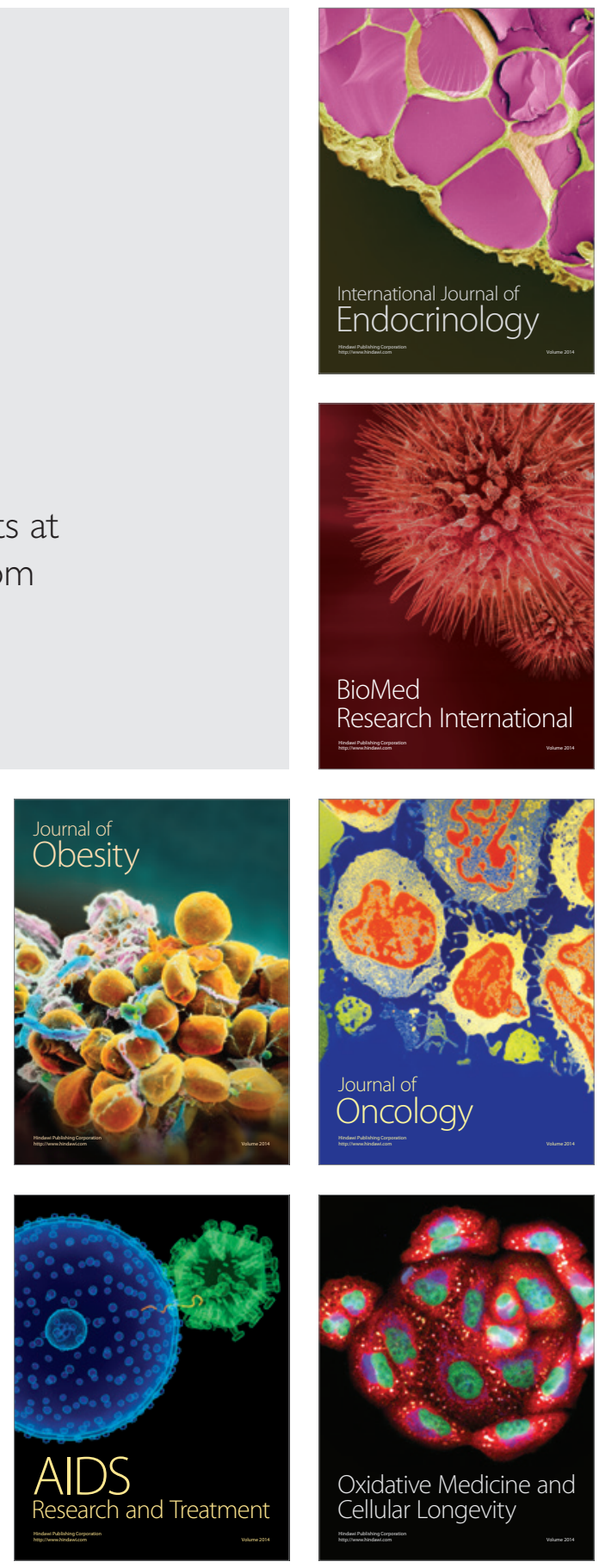